\title{
The Application of Satisfaction Survey of Rescue during 0206 Earthquake in the Promotion of Tainan City Marketing Strategies
}

\author{
Yuan-Ming Chiu ${ }^{1}$, Chun-Chu Liu ${ }^{2}$ \\ ${ }^{1}$ Chang Jung Christian University of Business and Operations Management, Taiwan \\ ${ }^{2}$ School of Continuing Education, Chang Jung Christian University, Taiwan \\ Email: yangming623@gmail.com
}

How to cite this paper: Chiu, Y.-M. and Liu, C.-C. (2018) The Application of Satisfaction Survey of Rescue during 0206 Earthquake in the Promotion of Tainan City Marketing Strategies. Journal of Power and Energy Engineering, 6, 1-13.

https://doi.org/10.4236/jpee.2018.63001

Received: November 30, 2017

Accepted: March 16, 2018

Published: March 19, 2018

Copyright $\odot 2018$ by authors and Scientific Research Publishing Inc. This work is licensed under the Creative Commons Attribution International License (CC BY 4.0).

http://creativecommons.org/licenses/by/4.0/

\begin{abstract}
The 0206 Earthquake, occurring on February 6, 2016, caused the collapse of the Yongkang-Wei Guan building in Tainan City, leading to the death of 115 people and trapping about three hundred people waiting for the rescue. No sooner had the earthquake occurred, the Tainan City Government Fire Department immediately set up a disaster response center and command center to dispatch the rescue team in time, which is appreciated by the citizens. A year after the earthquake, a survey is conducted, aiming to collect and reflect civic opinions and satisfaction on the rescue during 0206 earthquake. Therefore, the purposes of this study are as follows: 1 ) This survey will facilitate the Tainan city government to device future marketing strategies and continue to promote new policy. 2) This survey will guide Tainan City Government Fire Department on how to enhance the disaster rescue. 3) This survey will serve as the reference for other cities, intending to develop similar fire-fighting tactical strategies.
\end{abstract}

\section{Keywords}

City Marketing, Earthquake, Analysis of Satisfaction

\section{Introduction}

The main research object of this study is to conduct a survey, which is capable of collecting and reflecting civic opinions and satisfaction on the rescue during 0206 earthquake.

An earthquake measuring 6.4 on the Richter scale struck 28 kilometers northeast of Pingtung City on Taiwan's southwestern coast at 03:57 a.m. (local time). A residential building, named Weiguan Jinlong in Yongkang District, collapsed. 
The schematic diagram of Weiguan Jinlong building was shown as Figure 1 [1] $[2]$.

The Wei Guan building is a residential complex with nine 17-story RC buildings built in 1994 with a height $52 \mathrm{~m}$ and there were 99 households with 289 people living in this building. After the collapse of the building, $\mathrm{H}$ and I buildings were stacked, A and $G$ buildings and the remaining five building structures were distorted, resulting in search and rescue difficulties.

\section{Satisfaction Measurement}

The satisfaction scale is as follows: 1) simple satisfaction scale, 2) mixed scale, 3) expectational scale, 4) attitude scale, and 5) affect scale. In this study, a simple satisfaction scale is used as a measure of satisfaction to understand the actual needs of the user [3] [4]. In this study, the satisfaction is measured on a simple satisfaction scale [5] [6].

\section{Main Body}

\subsection{Figures and Tables}

In this study, urban marketing is defined as a city-based product, including a marketing company (city hall) product or service. Therefore, the satisfaction survey in this study will form the basis of city marketing strategies as for how the rescue ability of the Tainan City in the future will improve and enhance the image of Tainan city government. In the urban marketing aspect, the city marketing strategy in this study uses Kolter's image marketing aspect to explore. The theoretical structure of this study is shown as Figure 2.

\subsection{Formula and Equation}

1) Interview object: citizens who live in Tainan City and are over 20 years of age.

2) Interview time: October 2 to 6, 2016.

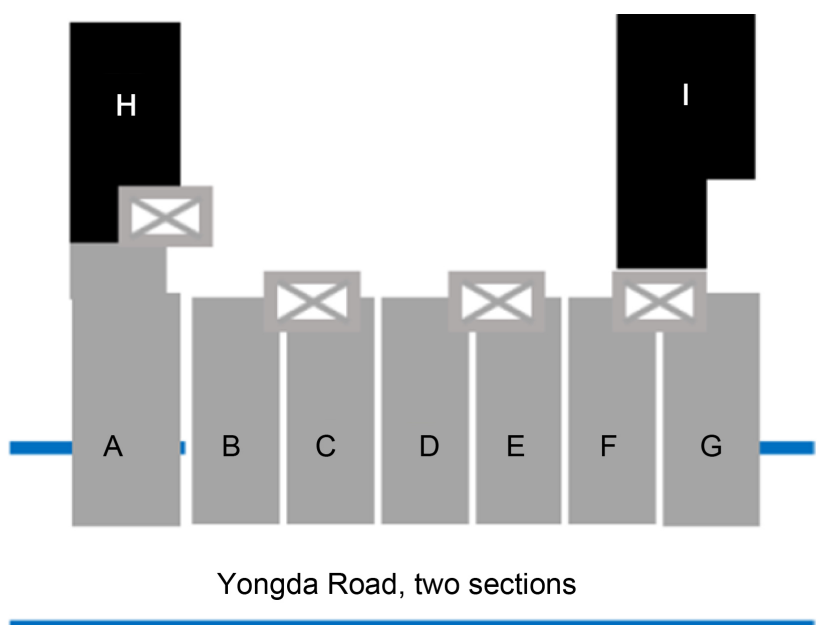

Figure 1. The schematic diagram of Weiguan Jinlong building. 


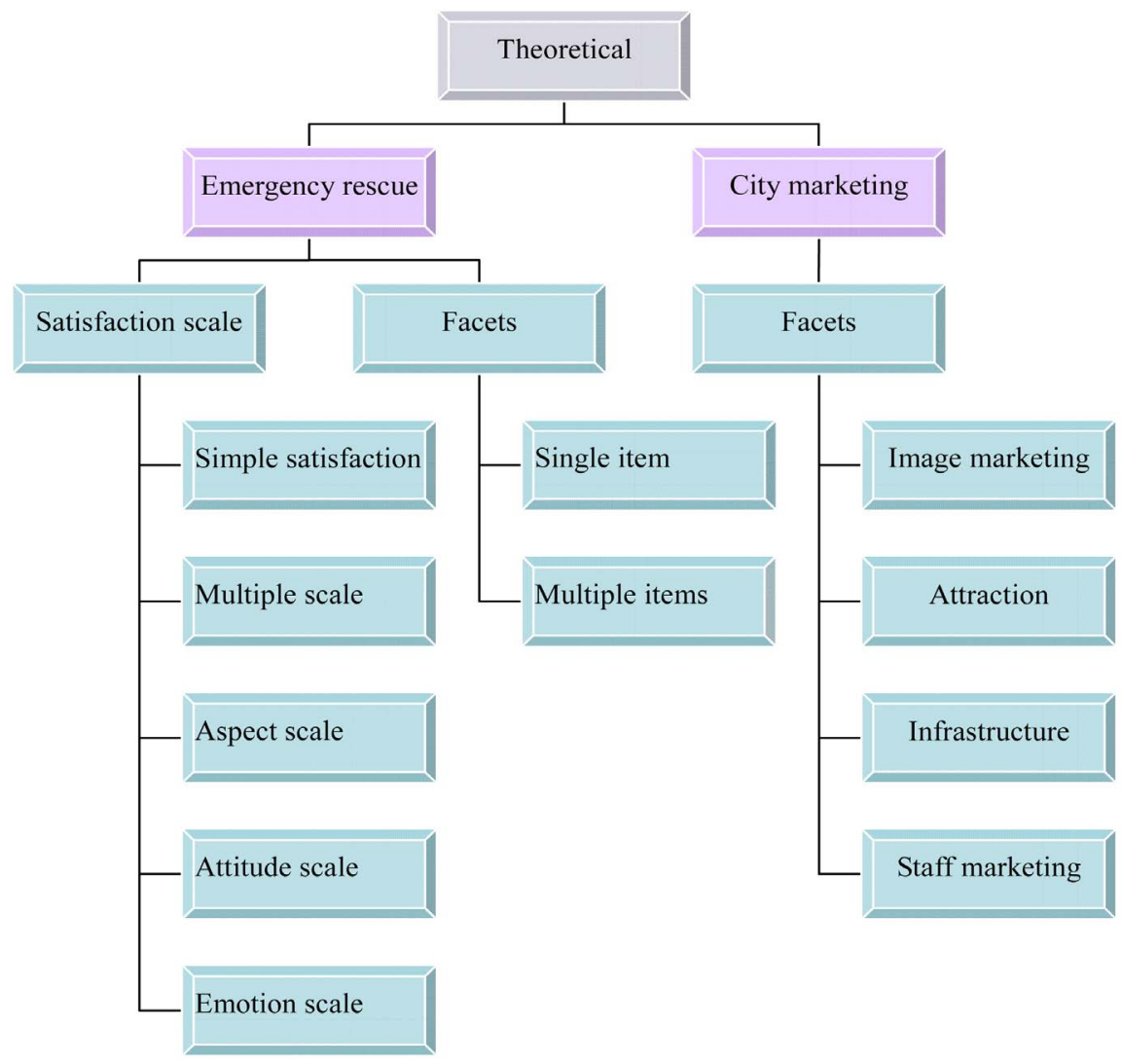

Figure 2. The theoretical structure of this study.

3) Interview method:

a) By calling

This survey was conducted through the computer-assisted telephone interviewing (CATI). After the completion of the visit training, excellent interviewers, who had participated in the company's large telephone interview and had multiple telephone interview experience, accessed interviewees in a specified period of time. In addition, in order to effectively control the interviewer and ensure the quality of the sample, the supervisor and the monitoring system and monitoring system were provided during the investigation to achieve the highest level of validity and reliability.

b) Interview quality control

The telephone interviewer performed telephone access within a specified period of time. At the same time, the progress and quality of the interviewer's telephone interview were controlled in the course of the investigation to effectively control the quality of the visit, through the interviewer's manual, questionnaire completion questionnaire, questionnaire survey form, supervisor configuration and questionnaire review. During the visit, the supervisor would also take the initiative to assist the telephone interviewer to solve the difficulties that might be encountered in order to facilitate the successful completion of the investigation in order to enhance the validity and reliability. If the access process did not meet the criteria, the telephone interviewer would be replaced to strictly control the 
quality of the survey.

c) Data review

After the visit was completed, the researcher and supervisor checked the contents of the information and review the relevance of the subject, whether the answers were contradictory or contrary to common sense. If any missing information or any logical contradictions were found, the work would be made immediately to confirm the completeness and reasonableness of all information.

d) Random sampling

Based on Tainan City residential telephone number table, a simple random sampling was used to investigate. In addition, in order to make the people, whose telephone number did not list in the telephone table, have the same extraction probability, random sampling was performed using random digit dialing (RDD). The survey completed 300 valid samples with a sampling error of less than $5.66 \%$ at $95 \%$ confidence limits. In this study, sampling error was obtained from the following formula.

$$
S E=Z_{1-\alpha} \sqrt{\frac{p \times q}{n} \times \frac{N-n}{N-1}}=1.96 \times \sqrt{\frac{0.5 \times 0.5}{300} \times \frac{1535580-300}{1535580-1}}=5.66 \%
$$

$S E$ : Sampling error.

$Z$ : Standard score. At the $95 \%$ confidence limits, the $\alpha$ value is 0.05 and the $Z$ value is 1.96 .

$p$ : Proportion, or probability of "success" in the model.

$q$ : Probability of "failure" in the model $(p+q=1$, so $q=1-p)$.

$p \times q$ : The maximum probability of success is obtained by assumed $p \times q=$ $0.5 \times 0.5$.

$N$ : Population proportion. According to the population information of Tainan City household registration office, citizens population over 20 years old in Tainan City were 1,535,580 at the end of August 2005.

$n$ : Sample size in this survey.

4) The outline of the survey:

a) People's Satisfaction with the Fire Bureau's Performance and Integrity.

People's satisfaction with the Fire Bureau's rescue performance in the "0206" earthquake. (Q1)

People's satisfaction with at-scene treatment given by the EMTs of the Fire Bureau. (Q2)

People's satisfaction with the management and allocation of rescue gear, equipment, and donations. (Q3)

People's satisfaction with the transparency of the information regarding the "0206" earthquake released by the Fire Bureau. (Q4)

People's satisfaction with the moral character of the Fire Bureau's firefighters. (Q5)

b) People's Satisfaction with Rescue Performance of Firefighters, Volunteer Firefighters, and Civil Rescue Groups.

If people know that firefighters, volunteer firefighters, and civil rescue groups 
all partook in the rescue mission of the "0206" earthquake. (Q6)

People's satisfaction with the rescue performance by firefighters. (Q7)

People's satisfaction with volunteer firefighters' rescue performance. (Q8)

People's satisfaction with the rescue performance by civil rescue groups. (Q9)

People's comments on the extent to which firefighters, volunteers, and civil rescue groups co-operated. (Q10)

The extent to which people approve of the importance of volunteer firefighters in the disaster response system. (Q11)

Suggestions to the Tainan City Government Fire Bureau. (Q12)

c) Information of the Respondents.

Gender/Age/Education/Occupation

5) The Analysis of the Statistics

a) Representative sample test

In order to understand whether the sample distribution is consistent with the distribution of the population and ensure the validity of the inference, the chi-square fitness test is used to proceed with representative sample test on the sample data group and the population group.

b) Frequency analysis

Through the distribution of each item in the population of the questionnaires, the overall frequency analysis of the subject was carried out. From the frequency and percentage of the data presented, the views of the respondents on the subject of the questionnaire and the overall profile of the relevant views can be understood.

c) Cross analysis

The results of each item and the basic information are evaluated for cross-analysis and the chi-square test. By selecting important segmentation variables, the variables with analytic significance are cross-analyzed. The data presented by the percentage after cross analysis can clearly show the difference between the segmentation variables and the variables.

Meanwhile, the results can be used to examine different types of respondents, whether there are significant differences in the views of various issues.

d) Decimal point carrying

The principle of rounding is used in terms of data presentation and the percentage adopts the first decimal place to show data results. Due to rounding off is used to assess the results, total percentages in part of items show more or less than $100 \%$ and are reasonable results.

e) Sample structure analysis

In order to make the survey results can be inferred as the opinions of the 20 years-older public in Tainan City, the sample data is weighted according to the gender and age structure of 20 years-older population in Tainan city. Moreover, in order to understand whether the weighting of effective samples is consistent with the population structure, two basic variables, gender and age, are used to proceed with representative sample test and the results are shown as Tables $1(a)-(c)$, respectively. The results show that there is no difference between the 
Table 1. (a) Sample representative test: gender. (b) Sample representative test: age. (c) Sample structure.

(a)

\begin{tabular}{|c|c|c|c|c|c|c|}
\hline \multirow[b]{2}{*}{ Gender } & \multicolumn{2}{|c|}{ Weighted Samples } & \multicolumn{3}{|c|}{ Parent Population } & \multirow[b]{2}{*}{ Result } \\
\hline & Samples & Percentage & $\begin{array}{c}\text { Parent } \\
\text { Population }\end{array}$ & $\begin{array}{c}\text { Expected } \\
\text { Samples }\end{array}$ & $\begin{array}{l}\text { Ratio of } \\
\text { Population }\end{array}$ & \\
\hline Male & 149 & $49.5 \%$ & 760,854 & 149 & $49.5 \%$ & \multirow{2}{*}{$\begin{array}{l}\text { - } \text { Chi square value }=0.0 \\
\text { - } P>0.05 \\
\text { - There was no significant difference } \\
\text { between the sample and the } \\
\text { parent }\end{array}$} \\
\hline Female & 300 & $100.0 \%$ & $1,535,580$ & 151 & $100.0 \%$ & \\
\hline \multicolumn{7}{|c|}{ (b) } \\
\hline & \multicolumn{2}{|c|}{ Weighted Samples } & \multicolumn{3}{|c|}{ Parent Population } & \multirow[b]{2}{*}{ Result } \\
\hline Age & Samples & Percentage & $\begin{array}{c}\text { Parent } \\
\text { Population }\end{array}$ & $\begin{array}{l}\text { Expected } \\
\text { Samples }\end{array}$ & $\begin{array}{c}\text { Ratio of } \\
\text { Population }\end{array}$ & \\
\hline $20-29$ & 50 & $16.6 \%$ & 255,219 & 50 & $16.6 \%$ & \multirow{6}{*}{$\begin{array}{l}\text { - Chi square value }=0.0 \\
\text { - } P>0.05 \\
\text { - There was no significant difference } \\
\text { between the sample and the } \\
\text { parent }\end{array}$} \\
\hline $30-39$ & 61 & $20.4 \%$ & 312,361 & 61 & $20.4 \%$ & \\
\hline $40-49$ & 56 & $18.6 \%$ & 285,880 & 56 & $18.6 \%$ & \\
\hline $50-59$ & 59 & $19.6 \%$ & 301,540 & 59 & $19.6 \%$ & \\
\hline 60 and above & 74 & $24.8 \%$ & 380,580 & 74 & $24.8 \%$ & \\
\hline Total & 300 & $100.0 \%$ & $1,535,580$ & 300 & $100.0 \%$ & \\
\hline
\end{tabular}

(c)

\begin{tabular}{|c|c|c|c|}
\hline & Basic Information & Frequency & Percentage \\
\hline \multirow{2}{*}{ Gender } & Male & 149 & $49.5 \%$ \\
\hline & Female & 151 & $50.5 \%$ \\
\hline \multirow{5}{*}{ Age } & $20-29$ & 50 & $16.6 \%$ \\
\hline & $30-39$ & 61 & $20.4 \%$ \\
\hline & $40-49$ & 56 & $18.6 \%$ \\
\hline & $50-59$ & 59 & $19.6 \%$ \\
\hline & 60 and above & 74 & $24.8 \%$ \\
\hline \multirow{6}{*}{ Education } & Elementary school or under & 35 & $11.6 \%$ \\
\hline & Junior high school & 33 & $11.0 \%$ \\
\hline & Senior high school & 87 & $29.0 \%$ \\
\hline & Two-year college & 35 & $11.7 \%$ \\
\hline & University & 80 & $26.7 \%$ \\
\hline & Graduate school and above & 30 & $10.0 \%$ \\
\hline \multirow{7}{*}{ Occupation } & Military, police, and civil servants & 16 & $5.2 \%$ \\
\hline & Administration supervisors, responsible persons and managers of a company (private sector) & 13 & $4.3 \%$ \\
\hline & Specialists (private sector) & 18 & $6.1 \%$ \\
\hline & Technicians and associate professionals (private sector) & 22 & $7.4 \%$ \\
\hline & Clerical workers (private sector) & 24 & $8.1 \%$ \\
\hline & Service and sales workers (private sector) & 36 & $12.1 \%$ \\
\hline & Agriculture, forestry, fishery, and animal husbandry workers (private sector) & 12 & $4.1 \%$ \\
\hline
\end{tabular}




\begin{tabular}{|c|c|c|c|}
\hline & Skilled workers and related workers (private sector) & 15 & $5.1 \%$ \\
\hline & Plant and machine operators, and assemblers (private sector) & 20 & $6.7 \%$ \\
\hline & Non-technical workers and manual workers (private sector) & 13 & $4.2 \%$ \\
\hline \multirow[t]{4}{*}{ Occupation } & Household workers & 48 & $15.9 \%$ \\
\hline & Students & 8 & $2.7 \%$ \\
\hline & Retired or unemployed & 54 & $18.1 \%$ \\
\hline & Others & 0 & $0.0 \%$ \\
\hline
\end{tabular}

weighted sample and the population. The results of this survey can be reasonably inferred to the population and can get academic support.

\section{f) Sample structure}

In the case of statistical analysis of single-choice questions, in addition to the frequency analysis, the respondents' basic information is used as the independent variable, and the chi-square test is used for cross analysis as well.

\subsection{Rescue and Honesty Satisfaction Analysis}

1) In this survey, it had dialed 2602 phone calls and completed 300 valid questionnaires in which the useful interview rate is $30.5 \%$. The detailed contact records are shown in Table 2.

2) The survey consists of 16 parts. Four of which are basic information of the respondents, and the rest of which are comments and suggestions of the respondents to the Tainan City Government Fire Bureau. Of the 12 parts, one of them is an open ended question, and the rest are multiple choice questions. The figures of percentage in frequency analysis are rounded to the nearest tenth. The sums in some parts may be over or under $100 \%$, which is normal as a result of rounding.

a) People's satisfaction with the progress of rescue mission in the "0206" earthquake.

The survey shows that $93.2 \%$ of the respondents are satisfied with the progress of rescue mission conducted by the Tainan City Government Fire Bureau. Of which includes "very satisfied" (28.1\%) and "satisfied" (65.1\%). The dissatisfaction rate is $3.9 \%$, of which includes "very dissatisfied" (0.5\%) and "dissatisfied" (3.4\%). The reasons of their dissatisfaction are listed in Table 3(a). In addition, $1.8 \%$ of the respondents answer "average/acceptable", and $1.1 \%$ of them answer "I don't know/no opinion".

b) People's opinions on EMTs' medical treatment at the disaster zone.

According to the analysis, $96.6 \%$ of the respondents are satisfied with the medical treatment given by the Tainan City Government Fire Bureau. Of which includes "very satisfied" (27.1\%) and "satisfied" (69.5\%). The dissatisfaction rate accounts for $2.5 \%$, which includes "very dissatisfied" (0.5\%) and "dissatisfied" (1.9\%). The reasons of their dissatisfaction are listed in Table 3(b). Besides, $0.5 \%$ of the respondents answer "average/acceptable", and $0.5 \%$ of them answer "I don't know/no opinion". 
Table 2. Contact records.

\begin{tabular}{|c|c|c|c|}
\hline & Contact situation & Times & Rate \\
\hline $\begin{array}{c}\text { Useful } \\
\text { interview (I) }\end{array}$ & Useful interview & 300 & $30.491 \%$ \\
\hline \multirow{3}{*}{$\begin{array}{c}\text { Refused } \\
\text { interview (R) }\end{array}$} & Refused by receivers & 560 & $56.91 \%$ \\
\hline & Refused by eligible respondents & 24 & $2.44 \%$ \\
\hline & Halfway refused by eligible respondents & 79 & $8.03 \%$ \\
\hline \multirow[t]{2}{*}{ Others $(\mathrm{O})$} & Language barriers & 21 & $2.13 \%$ \\
\hline & Useful contact times & 984 & $100.00 \%$ \\
\hline No contact & $\begin{array}{l}\text { Unavailable/on the phone/not } \\
\text { in right now }\end{array}$ & 34 & - \\
\hline Not eligible & & 49 & - \\
\hline \multirow{5}{*}{$\begin{array}{l}\text { Non-human } \\
\text { factors }\end{array}$} & Nobody answered & 740 & - \\
\hline & The line is busy & 79 & - \\
\hline & Telephone failure/stop & 29 & - \\
\hline & $\begin{array}{l}\text { Sample phone error/empty } \\
\text { number/missing number/fax }\end{array}$ & 687 & - \\
\hline & Phone call amounts & 2,602 & - \\
\hline
\end{tabular}

Useful interview rate: Useful interview times/useful contact times $=\mathrm{I} /(\mathrm{I}+\mathrm{R}+\mathrm{O})$.

c) People's opinions on the management and allocation of rescue gear, equipment, and donation.

The survey shows that $82.3 \%$ of the respondents are satisfied with the management and allocation of rescue gear, equipment, and donation handled by the Tainan City Government Fire Bureau. Of which includes "very satisfied" (14.5\%) and "satisfied" (67.8\%). The dissatisfaction rate is $10.6 \%$, which includes "very dissatisfied" (0.9\%) and "dissatisfied" (9.7\%). Their reasons of dissatisfaction are listed in Table 3(c). Besides, $2.7 \%$ of the respondents answer "average/acceptable", and 4.4\% answer "I don't know/no opinion".

d) The transparency of information regarding the "0206" earthquake released by the Tainan City Government Fire Bureau.

The survey shows that $82.1 \%$ of the respondents are satisfied with the transparency of information regarding the "0206" earthquake released by the Fire Bureau. Those who answer intransparent accounts for $13.3 \%$, and $4.6 \%$ of respondents answer "I don't know/no opinion".

e) People's opinions on firefighters' integrity.

According to the survey, $98.2 \%$ of the respondents think they have good moral character (honesty). Of which includes "very good" (34.1\%), and "good" (64.1\%). Besides, $0.2 \%$ of the respondents answer "bad", and $1.6 \%$ of them answer "average/acceptable". The survey shows that most citizens think the firefighters in Tainan City Government Fire Bureau have good integrity.

f) People's opinions on the degree to which firefighters, volunteer firefighters, and civil rescue groups cooperated. 
Table 3. (a) The reasons of people's dissatisfaction with the progress of rescue mission in the "0206" earthquake. (b) The reasons of people's dissatisfaction with EMTs' medical treatment at the disaster zone. (c) The reasons of people's dissatisfaction with the management and allocation of rescue gears, equipment, and donation. (d) The reasons people are dissatisfied with the degree to which firefighters, volunteer firefighters, and civil rescue groups cooperated. (e) People's suggestions to the Tainan City Government Fire Bureau.

(a)

\begin{tabular}{cc}
\hline Reasons of Dissatisfaction & Frequency \\
\hline $\begin{array}{c}\text { The rescue effort was too slow. } \\
\text { from Tainan were excluded. } \\
\text { Rescue teams from other cities/counties other than } \\
\text { The rescue effort was affected due to Fire Bureau's } \\
\text { inefficient command system. }\end{array}$ & 4 \\
Low efficiency due to a shortage of staff in the early stage & 1 \\
$\begin{array}{c}\text { The heavy machinery should be deployed in the earlier time. } \\
\text { The post-disaster recovery proceeded too slowly. } \\
\text { Information was unclearly integrated. } \\
\text { Short of staff. }\end{array}$ & 1 \\
\end{tabular}

(b)

\begin{tabular}{cc}
\hline Reasons of Dissatisfaction & Frequency \\
\hline $\begin{array}{c}\text { The rescue effort was too slow. } \\
\text { Tzuchi shouldn't have been involved. It should have } \\
\text { been conducted by the city government. }\end{array}$ & 2 \\
$\begin{array}{c}\text { Medical treatment was given too slowly at scene in the last phase. } \\
\text { The medical treatment I saw at the scene was not good enough. }\end{array}$ & 1 \\
\hline
\end{tabular}

(c)

\begin{tabular}{cc}
\hline Reasons of Dissatisfaction & Frequency \\
\hline $\begin{array}{c}\text { Supplies were dispensed too slowly. } \\
\text { Rescue equipment was inadequately prepared. }\end{array}$ & 7 \\
\hline $\begin{array}{c}\text { Supplies were not dispensed by a one-stop window. The affected people couldn't receive } \\
\text { supplies in a timely manner, and they were not fairly dealt out. }\end{array}$ & 3 \\
Supplies were dispensed in a disordered manner. No one was in charge of it. & 2 \\
$\begin{array}{c}\text { The government dispensed fewer supplies to the affected people in Yujing District and } \\
\text { mountain areas. It's not fair that people in the city got more while we had less. }\end{array}$ & 1 \\
$\begin{array}{c}\text { The government put Yujing District on the back burner until people complained. The } \\
\text { damaged buildings are still on the waiting list to be repaired. }\end{array}$ & 1 \\
Some people didn't know where to get supplies. & 1 \\
Firefighters' rescue equipment was too old and not in good condition. & 1 \\
The Fire Bureau dispatched rescue apparatus too slowly. & 1 \\
The compensation was not fairly dispensed. & 1 \\
The supplies didn't fit people's needs. & 1 \\
Information of donation was not transparent. & 1 \\
Insufficient medical equipment. & 1 \\
Equipment was not dispatched in a timely manner. & 1 \\
\hline
\end{tabular}


(d)

\begin{tabular}{|c|c|}
\hline Reasons of Dissatisfaction & Frequency \\
\hline Support rescue teams and resources were not well integrated and coordinated. & 7 \\
\hline The commander could have done a better job at commanding and dispatching. & 4 \\
\hline $\begin{array}{l}\text { There seemed to be some dispute and communication issues between firefighters } \\
\text { and civil rescue groups, which left some to be desired. }\end{array}$ & 2 \\
\hline There was no unified plan on dispatch of personnel. & 2 \\
\hline $\begin{array}{l}\text { The three sides did not cooperate well. Some civil rescue groups and volunteer } \\
\text { firefighters were not assigned any tasks, so manpower was wasted. The volunteer } \\
\text { firefighters and civil rescue groups couldn't do much due to lack of training. }\end{array}$ & 1 \\
\hline $\begin{array}{l}\text { The Fire Bureau didn't let volunteer firefighters and civil rescue groups know } \\
\text { their decisions, so it was difficult for them to cooperate. }\end{array}$ & 1 \\
\hline $\begin{array}{l}\text { There was some miscommunication between the support } \\
\text { rescue teams and the local rescue teams. }\end{array}$ & 1 \\
\hline $\begin{array}{l}\text { The Fire Bureau was unwilling to cooperate with volunteer } \\
\text { firefighters and civil rescue groups. }\end{array}$ & 1 \\
\hline $\begin{array}{l}\text { Tasks were not fairly assigned, and discordance existed between } \\
\text { different teams, so they acted separately. }\end{array}$ & 1 \\
\hline There were some issues about how personnel were assigned and dispatched. & 1 \\
\hline
\end{tabular}

(e)

Open Ended Opinions

Fire equipments and gears have to be renewed.

Firefighters' equipment has to be renewed to ensure their safety.

Many rescue groups were involved in this mission.

They could have been better dispatched and utilized.

The Fire Bureau has to educate people more about earthquake/fire safety and prevention.

Central government should allocate more budget to the Fire Bureau to purchase more fire equipment and apparatus.

Firefighters should do less unrelated jobs such as saving animals, catching snakes, and removing hives.

The Fire Bureau should recruit more firefighters to respond to disasters.

They should respond faster to disasters.

They need to train volunteer firefighters more.

Someone should have been in charge of managing supply dispersion in order to prevent disturbance of rescue tasks and supply delivery.

The mayor should have taken the helm of the command system, coordinated rescue teams, and planned affairs regarding rescue.

The Fire Bureau should introduce more high-tech detection equipment.

When the residential fire on Funong Street in East District broke out, it took a

long time for the firefighters to arrive. They should be more familiar with the streets of Tainan City in order to prevent delay.

Some fire apparatus should be designed specifically for narrow streets.

For example, the aerial ladder should be designed for narrow streets, and the fire hoses should be extended.

There should be a place for rescuers to dine at a disaster zone, so they can recover and do their best. 


\begin{tabular}{|c|c|}
\hline $\begin{array}{l}\text { They can invite colleges or communities to promote fire safety } \\
\text { to intensify people's awareness of disaster prevention. }\end{array}$ & 1 \\
\hline $\begin{array}{l}\text { Everyone should have followed the commander's orders, } \\
\text { so the rescue mission would have proceeded more smoothly. }\end{array}$ & 1 \\
\hline They should test every building's capacity of resistance to earthquakes. & 1 \\
\hline The order of the rescue and excavation were not fair. & 1 \\
\hline Total & 73 \\
\hline
\end{tabular}

The survey shows that $89.3 \%$ of the respondents are satisfied with the degree to which firefighters, volunteer firefighters, and civil rescue groups cooperated. Of which includes "very satisfied" (22.8\%), and "satisfied" (66.5\%). The percentage of "dissatisfied" is $8.8 \%$, and the reasons are listed in Table $3(\mathrm{~d})$. Besides, $0.8 \%$ of the respondents answer "average/acceptable", and $1.1 \%$ of them answer "I don't know/no opinion".

g) Comments and suggestions to the Tainan City Government Fire Bureau.

Of all the respondents, 70 of them provide us with their suggestions. Table $3(\mathrm{e})$ is a compilation of their suggestions.

\section{Conclusions and Recommendations}

From the survey results, the satisfaction rate of rescue effort made by the Tainan City Government Fire Bureau was $93.2 \%$; the satisfaction rate of emergency medical treatment of emergency medical technicians in the disaster scene was $96.6 \%$; and the satisfaction rate of disaster rescue equipments and donated supplies management and distribution was $82.3 \%$. Furthermore, in terms of honesty and efficiency, the satisfaction rate of the earthquake disaster information openness of Tainan City Government Fire Bureau was $82.1 \%$, and $98.1 \%$ respondents were satisfied with the moral integrity and honesty of the fire fighters.

In terms of disaster relief workers, $91.4 \%$ (of the) respondents were aware of the contribution made by official fire fighters. $97.6 \%$ (of the) respondents indicated that they were satisfied with rescue efforts of "volunteer fire fighters" in the 0206 earthquake. $94.1 \%$ (of the) respondents indicated that they were satisfied with rescue efforts made by "civil rescue associations" in the 0206 earthquake, $89.3 \%$ (of the) respondents expressed satisfaction with the overall coordination of official fire fighters, volunteer fire fighters and civil rescue associations in the 0206 earthquake, and $96.0 \%$ (of the) respondents agreed that volunteer fire fighters are the important part of the disaster rescue system. Based on the survey results of respondents, recommendations are obtained as following:

1) To keep high degree of disaster rescue satisfaction in the future, it is required to strengthen supplies management.

As items Q1 to Q3 presented, the public were highly satisfied with rescue efforts made by Tainan City Government Fire Bureau in the 0206 earthquake. However, as Q3 indicated, more than $10.6 \%$ (of the) respondents were dissatisfied with disaster rescue equipments, donated supplies management and distri- 
bution of Tainan City Government Fire Bureau during the rescue period. Therefore, it is recommended that the Tainan City Government Fire Bureau can set up one stop service of rescue supplies and set up a direct line, which are in charge of comprehensive coordination and deployment for all donated supplies donated by the public.

Furthermore, the information of supplies distribution standards should be open to the public, which allows people in need to access and assess what efforts the government has made.

2) It is still necessary to enhance the transparency of the rescue information openness.

Through the Q4 and Q5, it is known that the respondents had high satisfaction with the transparency of disaster information openness and the moral integrity of the fire. Nonetheless, there were still some respondents who felt the information during the rescue period was not open and transparent enough. Hence, the information of supplies distribution standards and how the rescue effort was made should be open to the public, which allows people in need to access and assess what efforts the government has made.

3) It is crucial to bolster the overall coordination during the rescue period in the future.

As Q10 suggested, some respondents were unsatisfied with the poor integration and coordination of mutual support between the official fire fighters, volunteer fire fighters and civil rescue associations. Therefore, it is recommended that Tainan City Government Fire Bureau can strengthen the coordination and cooperation by regularly holding trainings aimed to respond to large-scale disaster where official fire fighters, volunteer fire fighters and civil rescue associations have the opportunity to cooperate to deal with various kinds of challenges, thereby allowing the maximum efficiency of the staff and vehicles at the real disaster rescue scene.

This research, through a questionnaire survey, explores the civic satisfaction on 0206 earthquake disaster rescue, which can be used to shape the future trend of how to promote the marketing strategy of Tainan city and.

\section{References}

[1] Omori, F. (1907a) Earthquake of the Chiayi Area, Taiwan, 1906. Introduction of Earthquake, 103-147. (In Japanese)

[2] Omori, F. (1907b) Preliminary Note on the Formosa Earthquake of March 17, 1906. Bulletin of the Imperial Earthquake Investigation Committee, 1, 53-69.

[3] Oliver, R. (1981) Measurement and Evaluation of Satisfaction Process n Retail Sellings. Journal of Retailing, 57, 25-48.

[4] Hempel, D.J. (1977) Consumer Satisfaction with the Home Buying Process: Conceptualization and Measurement, In: Hunt, K., Ed., The Conceptualization of Consumer Satisfaction and Dissatisfaction, Marketing Science Institute, Cambridge, MA, 7.

[5] Locke, E.A. (1969) What Is Job Satisfaction. Organizational Behavior and Human 
Performance, 4, 309-336. https://doi.org/10.1016/0030-5073(69)90013-0

[6] Howard, J.A. and Sheth, J.N. (1969) The Theory of Buyer Behavior. John Wily \& Sons, New York. 